\title{
Current issues in the diagnostics of paediatric chronic rhinosinusitis
}

\author{
Arkadiusz Standyło ${ }^{1, A-E \oplus}$, Aleksandra Obuchowska' ${ }^{1, B-E \oplus}$, Tomasz Horoch ${ }^{2, D-E \oplus}$, \\ Grażyna Mielnik-Niedzielska2,A,E-F \\ ${ }^{1}$ Scientific Association at the Chair and Department of Pediatric Otolaryngology, Medical University, Lublin, Poland \\ ${ }^{2}$ Chair and Department of Pediatric Otolaryngology, Medical University, Lublin, Poland \\ $A$ - Research concept and design, B - Collection and/or assembly of data, C - Data analysis and interpretation, \\ $D$ - Writing the article, E - Critical revision of the article, F - Final approval of the article
}

Standyło A, Obuchowska A, Horoch T, Mielnik-Niedzielska G. Current issues in the diagnostics of paediatric chronic rhinosinusitis. J Pre-Clin Clin Res. 2021; 15(3): 134-136. doi: 10.26444/jpccr/140070

\section{Abstract}

Introduction and objective. Paediatric chronic rhinosinusitis (PCRS) is a common disease in children. It is defined as an ongoing inflammation of the nasal cavity and sinuses lasting for over 12 weeks. Due to prevalence in the population, PCRS is associated with a high healthcare and financial burden. During the examination, attention should be paid to symptoms that may suggest chronic rhinosinusitis (CRS), because it may be underdiagnosed. Due to the chronicity of the inflammatory process and the similarity of symptoms to allergic rhinitis and adenoid hypertrophy, diagnosis and treatment are difficult. In this review, guidelines from The European Position Paper on Rhinosinusitis and Nasal Polyps (EPOS) 2020 and recent literature reports from Medline and Scopus database are analysed.

Materials and methods. Information was obtained through a review and analysis of the PubMed Medline and Scopus databases.

Brief description of the state of knowledge. Diagnostic difficulties with CRS can be caused by many factors. The EPOS guidelines recommend flexible or rigid nasal endoscopy as a preliminary objective method to assist in the recognition of CRS. Computed tomography (CT) is not recommended for routine management; therefore, CT is the gold standard for imaging when establishing a PCRS diagnosis or preparing for sinus surgery. The use of conventional X-ray imaging for chronic rhinosinusitis is limited and not recommended.

Conclusions. Understanding the symptoms of chronic rhinosinusitis is of utmost importance in daily practice. Early initial assessment of symptoms in children with a high probability of CRS allows for early diagnosis and reduces the need for endoscopic and imaging examination.

\section{Key words}

adolescent, child, otolaryngology, sinusitis, rhinitis, Diagnostic Techniques and Procedures

\section{INTRODUCTION}

Paediatric chronic rhinosinusitis (PCRS) is defined as an ongoing inflammation of the nasal cavity and sinuses lasting for over 12 weeks [1]. For diagnosis, two or more symptoms need to be observed, at least one of which is listed in from 'Main Symptoms' (Tab. 1). The symptoms should be confirmed in a face-to-face conversation or telemedicine call [1]. Chronic cough, prolonged nasal drainage and behavioural difficulties are important symptoms in paediatric patients $[2,3]$.

The estimated prevalence of chronic rhinosinusitis (CRS) in paediatric patients has been calculated to be between $2.1 \%-4 \%$ [4]. Children between the ages of $10-15$ years most often suffer from CRS. Moreover, in this age group, chronic sinusitis was more common than otitis media [1]. Due to prevalence in the population, PCRS is associated with a high healthcare and financial burden. Frequent visits to a clinic cause children to miss classes at school; furthermore, CRS affects the quality of life and learning ability [5]. Because PCRS has a complex aetiology and pathophysiology it is important to perform differential

Address for correspondence: Aleksandra Obuchowska, Scientific Association at the Chair and Department of Pediatric Otolaryngology, Medical University, Lublin, Poland

E-mail: aobuchowska12@gmail.com

Received: 08.06.2021; accepted: 08.07.2021; first published: 19.07.2021
Table 1. EPOS 2020 Clinical definition of chronic rhinosinusitis in children

\begin{tabular}{ll}
\hline Main & Nasal blockage \\
\cline { 2 - 2 } Symptoms & Obstruction \\
\cline { 2 - 2 } & Congestion \\
\cline { 2 - 2 } & $\begin{array}{l}\text { Discoloured nasal discharge } \\
\text { (anterior/posterior nasal drip) }\end{array}$ \\
\hline Additional & Facial pain or pressure \\
Symptoms & \\
\cline { 2 - 2 } & Cough \\
\end{tabular}

Reduction or loss of smell

diagnosis prior to treatment. Due to the chronicity of the inflammatory process and the similarity of symptoms to allergic rhinitis and adenoid hypertrophy, diagnosis and treatment are difficult. Depending on age, specific factors that contribute to rhinosinusitis are distinguished: adenoiditis in younger children and allergic rhinitis in older children [6]. Inflammation, mucociliary dysfunction and changes in 

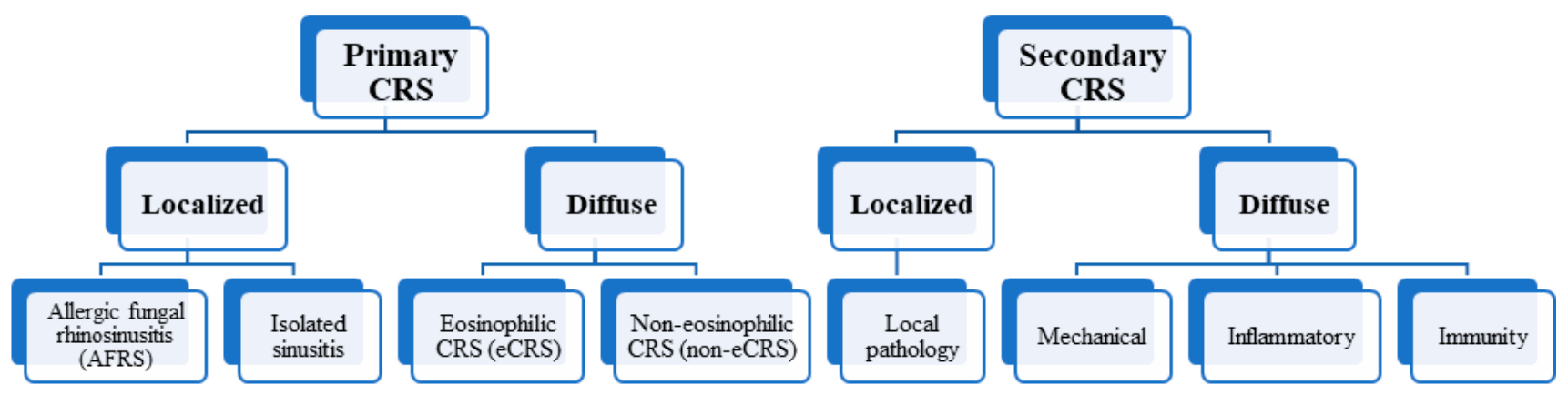

Figure 1. New classification for CRS according to EPOS 2020

the microbial environment are risk factors for the disease [1]. In addition, recent research has focused on the nasal microbiome and its role in infection and inflammation $[2,7$, 8]. It is worth mentioning that passive and active smoking is associated with chronic rhinosinusitis in children [1].

In this review, guidelines from The European Position Paper on Rhinosinusitis and Nasal Polyps (EPOS 2020) and recent literature reports from the Medline and Scopus databases were analysed. The articles present the most up-todate guidelines for symptomatology, diagnosis and treatment in children with chronic sinusitis.

Current state of knowledge. A new classification for CRS was proposed in the EPOS 2020 guidelines (Fig. 1) [1]. Compared to previous versions of EPOS guidelines, paediatric CRS aspects have been significantly expanded.

During the examination, attention should be paid to symptoms that may suggest chronic rhinosinusitis, because it may be underdiagnosed. In patients reporting to an otolaryngologist, the main symptoms are characterized by high sensitivity and low specificity [6]. Most of the diagnostic tools used in adults can also be used in children [9]. Diagnostic difficulties for CRS can be caused by many factors: false positive diagnoses may be caused by difficulty in differentiating CRS from adenoid hypertrophy, adenoiditis, rhinitis (including allergic rhinitis), incomplete evaluation by nasal endoscopy or imaging and deficient follow-up estimation in some patients [10].

The EPOS guidelines recommend flexible or rigid nasal endoscopy as a preliminary objective method to assist in the recognition of CRS $[1,11]$. This examination assesses the presence of purulent drainage, mucosal oedema, nasal polyps and adenoid pathology. In addition, in anterior rhinoscopy, the nasal septum, the middle canal, inferior turbinate, mucus secretion and the appearance of the mucosa should be assessed [12]. However, this type of examination may be demanding for the examiner in paediatric patients, especially with an uncooperative patient [13]. If there is a suspicion of refractory CRS, additional tests should be conducted (Fig. 2) [1, 9].

Computed tomography (CT) is not recommended for routine management; however, it can support navigation during surgical procedures and provide high sensitivity for mucosal inflammation [6]. Radiographic findings such as air-fluid level, opacification (partial or complete), and 4 $6 \mathrm{~mm}$ thickening of the mucus membrane suggest ongoing sinusitis [9]. CT is the gold standard for imaging when establishing a PCRS diagnosis or preparing for sinus surgery, particularly a non-contrasted CT with axial, coronal, and sagittal views. CT is recommended in patients with PCRS in whom conservative treatment and / or adenoidectomy did not control the symptoms of the disease, and in patients with suspected complications $[1,14]$. Certain types of chronic sinusitis, such as allergic fungal sinusitis and cystic fibrosis, are clearly visible on CT imaging [13]. Nevertheless, there are some limitations that must be taken into consideration, thus the routine use of CT is not recommended in children due to radiation vulnerability [10]. To reduce radiation, special computed tomography protocols for children have been developed [15].

Magnetic Resonance Imaging (MRI) is another medical imaging technique. The lack of exposure to radiation makes MRI a safer choice in the diagnosis of CRS. The downside is that MRI does not reveal bone details that are often required when considering surgical interventions [16]. The use of conventional X-ray imaging for chronic rhinosinusitis is limited [14].

In chronic disease, it is important to achieve and maintain clinical control of the disease, which is the primary goal of any treatment. This is defined as a condition in which the patient has no symptoms of the disease, or the symptoms do not affect their quality of life. The idea of control of CRS is relatively new [10]. Tools for assessing various aspects of disease control in CRS are described in the literature and

\section{Suspicion of refractory CRS}

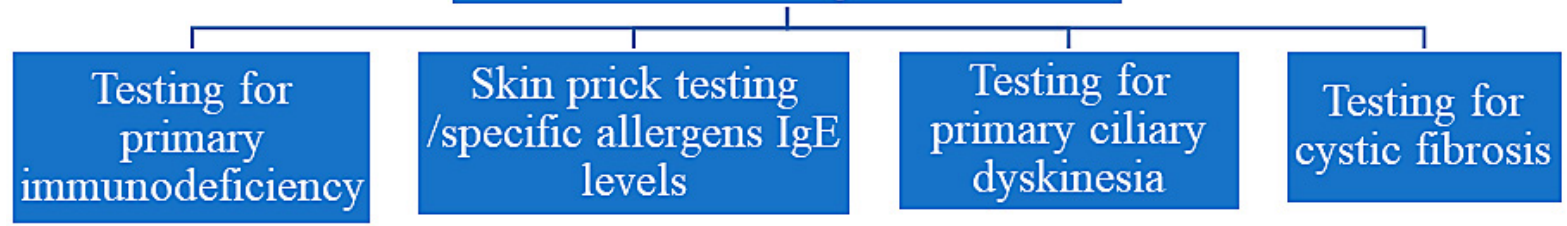

Figure 2. Additional tests to diagnose refractory CRS 
consist of questionnaires on the quality of life, the severity of symptoms or endoscopic evaluation systems [10, 17].

The proposed CRS follow-up test takes into the interpretation the presence and severeness of the symptoms listed in Table 2. Evaluation of the current clinical CRS control is reviewed within the last month. The current clinical control is divided into controlled, partly controlled (at least one symptom is present) and uncontrolled (three or more symptoms are present) [10].

Table 2. Symptoms for current clinical control of CRS assessment

\begin{tabular}{ll}
\hline Symptoms & nasal blockage \\
\cline { 2 - 2 } postnasal drip or rhinorrhoea \\
impaired smell ability \\
\hline sleep disturbance \\
endoscopic nasal evaluation \\
\hline need for oral medication \\
\hline
\end{tabular}

\section{CONCLUSIONS}

Understanding the symptoms of chronic rhinosinusitis is of the utmost importance in daily practice. Early initial assessment of symptoms in children with a high probability of CRS allows for early diagnosis and reduces the need for endoscopic and imaging examination. A diagnosis based on the main symptoms should be particularly useful for general practitioners and paediatricians. Imaging tests, such as CT or MRI, can be useful in confirming the diagnosis. The importance of the concept of disease control is vital in a clinical and research context; therefore, there is a need for a gold standard for disease control assessment in CRS.

\section{REFERENCES}

1. Fokkens WJ, Lund VJ, Hopkins C, et al. Executive Summary of EPOS 2020 Including Integrated Care Pathways. Rhinology. 2020; 58(2): 82-111. https://doi.org/10.4193/Rhin20.601

2. Park IH, Lee JS, Park JH, et al. Comparison of the human microbiome in adults and children with chronic rhinosinusitis. PLoS ONE. 2020; 15(12). https://doi.org/10.1371/journal.pone.0242770

3. Leo G, Incorvaia C, Cazzavillan A, et al. May chronic rhinosinusitis in children be diagnosed by clinical symptoms? Int J Pediatr Otorhinolaryngol. 2015; 79(6): 825-828. https://doi.org/10.1016/j. ijporl.2015.03.011.

4. Snidvongs K, Sangubol M, Poachanukoon O. Pediatric Versus Adult Chronic Rhinosinusitis. Curr Allergy Asthma Rep. 2020; 20(29). https:// doi.org/10.1007/s11882-020-00924-6

5. Anamika A, Chakravarti A, Kumar R. Atopy and Quality of Life in Pediatric Chronic Rhinosinusitis. Am J Rhinol Allergy. 2019; 33(5): 586-590. https://doi.org/10.1177/1945892419854266

6. Chandy Z, Ference E, Lee JT. Clinical Guidelines on Chronic Rhinosinusitis in Children. Curr Allergy Asthma Rep. 2019; 19(2): 14. https://doi.org/10.1007/s11882-019-0845-7

7.Stapleton AL, Shaffer AD, Morris A, et al. The microbiome of pediatric patients with chronic rhinosinusitis. Int Forum Allergy Rhinol. 2021; 11(1): 31-39. https://doi.org/10.1002/alr.22597

8. Drago L, Pignataro L, Torretta S. Microbiological Aspects of Acute and Chronic Pediatric Rhinosinusitis. J Clin Med. 2019; 8(2): 149. https:// doi.org/10.3390/jcm8020149

9. Badr DT, Gaffin JM, Phipatanakul W. Pediatric Rhinosinusitis. Curr Treat Options Allergy. 2016; 3(3): 268-281. https://doi.org/10.1007/ s40521-016-0096-y

10. Fokkens WJ, Lund VJ, Hopkins C, et al. European Position Paper on Rhinosinusitis and Nasal Polyps 2020. Rhinology. 2020; 58(29): 1-464. https://doi.org/10.4193/Rhin20.600

11. Beswick DM, Messner AH, Hwang PH. Pediatric Chronic Rhinosinusitis Management in Rhinologists and Pediatric Otolaryngologists. Ann Otol Rhinol Laryngol. 2017; 126(9): 634-639. https://doi. org/10.1177/0003489417719717

12. Brietzke SE, Shin JJ, Choi S, et al. Clinical consensus statement: pediatric chronic rhinosinusitis. Otolaryngol Head Neck Surg. 2014; 151(4): 542-553. https://doi.org/10.1177/0194599814549302

13. Stenner M, Rudack C. Diseases of the nose and paranasal sinuses in child. GMS Curr Top Otorhinolaryngol Head Neck Surg. 2014; 13(10). https://doi.org/10.3205/cto000113

14. Belcher R, Virgin F. The Role of the Adenoids in Pediatric Chronic Rhinosinusitis. Med Sci. 2019; 7(2): 35. https://doi.org/10.3390/ medsci7020035

15. Arcimowicz M, Niemczyk K. EPOS 2020: What's new for physician practitioners? Pol Otorhino Rev. 2020 Jun; 9(2): 7-17.

16. Heath J, Hartzell L, Putt C, et al. Chronic Rhinosinusitis in Children: Pathophysiology, Evaluation, and Medical Management. Curr Allergy Asthma Rep. 2018; 18(7): 37. https://doi.org/10.1007/s11882-018-0792-8

17. Ni JS, Kompelli AR, Nguyen SA, et al. The Sinus and Nasal Quality of Life Survey (SN-5) in the Management of Pediatric Chronic Rhinosinusitis: A systematic review and meta-analysis. Int J Pediatr Otorhinolaryngol. 2018; 111: 162-169. https://doi.org/10.1016/j.ijporl.2018.06.010. 